\title{
Manufacturing of Tool Steels by PBF-EB
}

\author{
Alexander Kirchner *, Burghardt Klöden, Marie Franke-Jurisch, Luis Inarra Rauh-Hain and Thomas Weißgärber
}

Citation: Kirchner, A.; Klöden, B.;

Franke-Jurisch, M.; Inarra

Rauh-Hain, L.; Weißgärber, T.

Manufacturing of Tool Steels by

PBF-EB. Metals 2021, 11, 1640.

https://doi.org/10.3390/

met11101640

Academic Editors:

Andrzej Miklaszewski and Eric Hug

Received: 30 August 2021

Accepted: 9 October 2021

Published: 14 October 2021

Publisher's Note: MDPI stays neutral with regard to jurisdictional claims in published maps and institutional affiliations.

Copyright: (c) 2021 by the authors. Licensee MDPI, Basel, Switzerland. This article is an open access article distributed under the terms and conditions of the Creative Commons Attribution (CC BY) license (https:// creativecommons.org/licenses/by/ $4.0 /)$.
Fraunhofer Institute for Manufacturing Technology and Advanced Materials IFAM, 01277 Dresden, Germany; burghardt.kloeden@ifam-dd.fraunhofer.de (B.K.); marie.franke-jurisch@ifam-dd.fraunhofer.de (M.F.-J.); luis.inarra.rauh-hain@ifam-dd.fraunhofer.de (L.I.R.-H.); thomas.weissgaerber@ifam-dd.fraunhofer.de (T.W.)

* Correspondence: alexander.kirchner@ifam-dd.fraunhofer.de

\begin{abstract}
Additive manufacturing (AM) of metals is stimulating the tool making industry. Moreover, besides the production of lost forms, AM processes are now being used to directly generate tools, molds or parts, leading to massive time savings. In the case of material development for AM, the challenge is to operate with carbon-containing iron-based materials distinguished by high strength and hardness, as well as high corrosion resistance and thermal conductivity. Often, those materials are susceptible to crack formation during processing. Using Electron Beam Powder Bed Fusion (PBF-EB), the challenge of crack formation can be overcome by using high process temperatures in the range $800-900{ }^{\circ} \mathrm{C}$. In this paper, results on the processing of a cold-working tool steel (X65MoCrWV3-2) and a hot-working steel (X37CrMoV5-1) will be presented. These include the processing window, processing strategies to minimize the density of cracks and properties with respect to microstructure and hardness.
\end{abstract}

Keywords: additive manufacturing; powder bed fusion; selective electron beam melting; tool steel

\section{Introduction}

The term tool steel refers to a group of iron-based alloys suitable for manufacturing shaping tools. These steels are characterized by their high hardness, yield strength and resistance against abrasion. To achieve these properties, special care needs to be taken during the manufacturing of tool steels to yield high purity and homogeneity. The subgroup of cold-working tool steels is intended for operating temperatures below $200{ }^{\circ} \mathrm{C}$. Generally, high content of carbon and alloying elements increase hardenability. Furthermore, high carbide content increases abrasion resistance but lowers toughness. High-speed steels extend the application range to higher temperatures, thus enabling their use at higher cutting speed. This is achieved by adding chromium, tungsten, molybdenum, and vanadium. In contrast, hot-working steels exhibit hardness, strength, and toughness at elevated temperatures up to approximately $100{ }^{\circ} \mathrm{C}$ below their annealing temperature. This is achieved using a low carbon content but a substantial amount of alloying elements such as chromium and tungsten. Resistance to thermal shock and optimum thermal conductivity are additional properties desired in hot-working steels.

The additive manufacturing of tool steels by powder bed fusion (PBF) offers several benefits. First, geometrically complex parts can be fabricated in near-net shape. This enables the thermal optimization of tools by the adoption of conformal cooling channels. In addition, direct additive fabrication on demand leads to shorter production cycles and aids faster product development. Finally, with small melt pools and very high solidification rates, $\mathrm{PBF}$ technologies have the potential to suppress segregation tendencies and fabricate highly homogeneous material.

Two main PBF processes exist: Laser Beam Powder Bed Fusion (PBF-LB) and Electron Beam Powder Bed Fusion (PBF-EB). They share the principle of generation of thin powder layers and selective melting by a scanning beam. In PBF-LB the heat source is a laser, while in PBF-EB an electron beam is employed. The energy transfer is different, such that the 
electron beam penetrates deeper into the particulate material. Therefore PBF-EB is more preferable for the melting of materials like pure copper or aluminum. Their high thermal conductivity and the reflection of the laser can cause process instabilities and require special lasers in PBF-LB [1]. Further challenges arise upon high residual stresses in the final parts due to fast cooling rates and thermal gradients for both technologies. For process stability, in PBF-EB a light sintering of the powder bed is required before the melting step [2]. The sintering is accompanied by an increased temperature in the powder bed of up to about $1000^{\circ} \mathrm{C}$, thus leading to reduced residual stresses in the resulting parts. Due to the lack of powder bed heating in PBF-LB, brittle materials like nickel-based, some aluminum, and refractory alloys or carbon-rich tool steels have a greater propensity for crack formation and part distortion compared to PBF-EB [3-6]. Therefore, substrate heating or special scanning strategies are used to avoid excess residual stress formation $[3,7,8]$. However, due to the generally finer powders in PBF-LB, the risk of sintering due to substrate heating must be avoided, whereas temperatures like those for PBF-EB are not recommended. Additionally, the PBF-EB process operates under vacuum, while PBF-LB operates under an inert atmosphere typically.

The best studied and most widely used tool steels for PBF are carbon-free maraging steels, such as $13 \mathrm{Ni}-300[9,10]$. A wide range of properties, both as-built and after heat treatment, have been reported. Influencing factors are seen in powder properties, scan strategies, processing parameters, and choice of suitable heat treatment. Optimum tensile strength reached $1300 \mathrm{MPa}$ as-built and $2100 \mathrm{MPa}$ heat-treated. However, ductility and toughness remained markedly below conventional material.

The processing of carbon-bearing tool steels by PBF has been investigated in several studies. However, due to the formation of internal stresses and cracks during cooling, these attempts proved challenging [11,12]. The majority of studies have focused on the widely used X40CrMoV5-1 (AISI H13) steel. In PBF-LB, preheating the base plate to about $300{ }^{\circ} \mathrm{C}$ was found to be crucial for the suppression of cracks. This is explained by lowered thermal gradients and reduced thermal stresses. $99.7 \%$ density has been reached for a volumetric laser energy density of $60 \mathrm{~J} / \mathrm{mm}^{3}$ [13]. The as-built microstructure consists of dendrites with retained austenite in the interdendritic regions. The cell sizes depend on process parameters and range from $0.5 \mu \mathrm{m}$ to $2 \mu \mathrm{m}$. Using atom probe tomography an enrichment of the alloying elements $\mathrm{V}, \mathrm{Cr}, \mathrm{Mn}, \mathrm{Mo}$, and $\mathrm{C}$ in the interdendritic regions is established. In the as-built state, hardness values from $570 \mathrm{HV}$ up to $745 \mathrm{HV}$ have been reported. The range of the measured tensile properties is accordingly wide. Using a preheating temperature of $400{ }^{\circ} \mathrm{C}$ and an ultimate tensile strength of $1965 \mathrm{MPa}$ was established [14]. This is comparable to heat-treated conventional material, reflecting the fully martensitic state of this material. Nevertheless, the elongation at break is significantly lower, at $4.1 \%$. The positive effect of post treatment, especially hot isostatic pressing, on PBF-LB-fabricated X40CrMoV5-1 has been shown [15]. The PBF-EB processing of X40CrMoV5-1 has been demonstrated as well [16]. Hardness values of $46 \mathrm{HRC}$ to $50 \mathrm{HRC}$ and an ultimate tensile strength of $1400 \mathrm{MPa}$ have been established [17]. The mechanical properties, especially the elongation at fracture, are influenced by the defect structure [18]. A needle-like microstructure, likely consisting of bainite and martensite, is observed. A distinct influence of build height on as-built hardness is found.

Concerning X37CrMoV5-1 (AISI H11), several studies using PBF-LB have been published, but none using PBF-EB. The PBF-LB processing and the obtained microstructure is very similar to X40CrMoV5-1 [19]. Without the need for a quench-hardening step, the ultimate tensile strength after annealing reached $2148 \mathrm{MPa}$, and the elongation at break $8.8 \%$ [20].

From the group of cold-working tool steels, $\mathrm{X} 65 \mathrm{MoCrWV3}-2$ has been processed using PBF-LB [21]. A porosity below $0.5 \%$ was achieved, and the crack density was reduced by means of preheating. The microstructure shows of fine cellular-dendritic subgrains superimposed with martensite. Inhomogeneous hardness distribution indicates in situ tempering effects by melting of subsequent layers. As-built hardness was in the $620 \mathrm{HV} 0.1$ 
to 740 HV0.1 range [22]. The highly alloyed cold-working tool steel Uddeholm Vanadis 4 Extra (C: 1.4, Cr: 4.7, Mo: 3.5, and V: 3.7 in wt-\%) has been additively processed using PBF-EB [23,24]. Employing powder bed temperatures up to $1000{ }^{\circ} \mathrm{C}$ and area energies between 1.5 and $2.0 \mathrm{~J} / \mathrm{mm}^{2}$, dense specimens were obtained. The fine grains were elongated in build direction and carbides precipitated along the grain boundaries. As-built hardness was $55 \mathrm{HRC}$ to $58 \mathrm{HRC}$.

Belonging to the group of high-speed steels, AISI M2 was examined for processing in PBF. For PBF-LB, the heating of the base plate to at least $200{ }^{\circ} \mathrm{C}$ was found to be crucial for the production of crack-free parts [3]. A maximum density of $99.8 \%$ was achieved. This was attributed to reduced thermal gradients. The as-built material contains significant amounts of austenite. Applying a remelting strategy, this was converted into martensite, resulting in up to $64 \mathrm{HRC}$ hardness. The microstructure formed during rapid solidification of M2 in PBF-LB was studied in detail using transmission electron microscopy [25]. Three different zones consisting of ferrite, ferrite/austenite, and ferrite/austenite/martensite have been identified. The ferrite lattice constant was found enlarged by V, Cr, Mo, W, and Si. Recently, the columnar-to-equiaxed transition in PBF-LB of M2 was studied [26]. An experimental parameter study was used together with numerical model predictions to construct a process map with columnar and highly equiaxed regions.

This study aims at applying the advantages of PBF-EB, namely the high preheat temperature of the powder bed, the low risk of contamination from the atmosphere, and the comparatively high build rate, to a cold-working tool steel (X65MoCrWV3-2) and a hot-working steel (X37CrMoV5-1). To this end, PBF-EB process parameters were developed, resulting in respective parameter windows. Initially, the build quality was assesses by metallographic analysis of porosity and microstructure. The chemical composition of the PBF-EB material was compared to the feedstock. The tensile properties of PBF-EB X37CrMoV5-1 were characterized. Hardness was measured for both materials in the as-built and heat-treated state.

\section{Materials and Methods}

Gas atomized feedstock was obtained in the particle fraction 50-150 $\mu \mathrm{m}$ from Dörrenberg Edelstahl GmbH (X65MoCrWV3-2) and in the particle fraction 45-125 $\mu \mathrm{m}$ from Deutsche Edelstahlwerke Specialty Steel GmbH \& Co KG (X37CrMoV5-1, Printdur 2343). The particle size distributions of the powder were characterized according to ISO 13320 in a laser scattering Horiba LA950 analyzer (Horiba Ltd., Kyoto, Japan). Flowability was measured for $50 \mathrm{~g}$ of powder by means of a calibrated funnel with $2.54 \mathrm{~mm}$ diameter (Hall flowmeter, DIN ISO 4490). Apparent density was established by fill density funnel method (DIN EN ISO 3923-1). Tap density was measured on a Scott volumeter according to DIN ISO 3953. The chemical composition of powder and solid specimen was measured using a Thermo Scientific 6300 DUO ICP-OES (Thermo Fisher Scientific, Waltham, MA, USA) after solving the sample in hydrochloric acid. For O and N TCH600/LECO and for C CS230/LECO were used.

PBF-EB was performed on an Arcam A2X (Arcam AB, Gothenburg, Sweden) machine using software version EBM Control 3.2. Before starting a build process, the chamber was evacuated to at least $1 \times 10^{-4}$ mbar. Afterwards, helium pressure of $2 \times 10^{-3} \mathrm{mbar}$ was employed. The acceleration voltage of the electron gun was $60 \mathrm{kV}$. At the beginning of a build job, a $150 \mathrm{~mm} \times 150 \mathrm{~mm}$ steel start plate was heated to $875^{\circ} \mathrm{C}$, as measured by thermocouple underneath. The choice of this temperature facilitates sintering of the powder around the start plate. The addition of each layer started by raking a powder film of $70 \mu \mathrm{m}$ nominal thickness. The fresh powder was preheated by fast scanning with a defocused electron beam. For melting a cross snake scan strategy was chosen. Beam currents ranging from $3 \mathrm{~mA}$ to $25 \mathrm{~mA}$ were used, corresponding to $200 \mathrm{~W}$ to $1500 \mathrm{~W}$ beam power. Scan speeds employed were between $750 \mathrm{~mm} / \mathrm{s}$ and 10,000 mm/s. Hatch distances between $0.05 \mathrm{~mm}$ und $0.2 \mathrm{~mm}$ were considered. After each layer, the principal scan direction was rotated $90^{\circ}$. Upon completion, the build was cooled down in the 
chamber and excess powder was removed by nitrogen jet blasting. For recycling, the excess powder was screened using a $180 \mu \mathrm{m}$ sieve.

Selected specimens were heat-treated. X65MoCrWV3-2 samples were austenitized at $1050{ }^{\circ} \mathrm{C}$ for $20 \mathrm{~min}$ before quenching in water [27]. For X37CrMoV5-1 hardening consisted of austenitizing at $1030^{\circ} \mathrm{C}$ for $20 \mathrm{~min}$ followed by oil quenching [28]. To increase toughness, tempering was done twice at $500{ }^{\circ} \mathrm{C}, 550{ }^{\circ} \mathrm{C}$, and $600^{\circ} \mathrm{C}$, respectively, for $2 \mathrm{~h}$. Hardness was measured on an Innovatest Falcon 500 (HV10) (Innovatest GmbH, Selfkant-Heilder, Germany) according to DIN EN ISO 6507-1. For tensile tests flat specimens with $2 \mathrm{~mm}$ thickness, $6 \mathrm{~mm}$ thickness, and $24 \mathrm{~mm}$ length of the reduced section according to DIN EN ISO 6892-1 were cut from blanks using electrical discharge machining. Tensile tests were performed on a Zwick 1476 machine (ZwickRoell GmbH \& Co. KG, Ulm, Germany) at room temperature and a deformation rate of $0.45 \mathrm{~mm} / \mathrm{min}$. Seven specimen were tested for both in build direction (z) and perpendicular to it $(x, y)$. For metallographic analysis, specimens were cut, mounted and polished. To reveal the microstructure, polished samples were etched with V2A etchant. Scanning electron microscopy (SEM) and energy-dispersive X-ray spectroscopy (EDX) were performed on a Zeiss EVO 50 XVP (Carl Zeiss GmbH, Oberkochen, Germany). Thermal diffusivity was measured on $10 \mathrm{~mm} \times 10 \mathrm{~mm} \times 2.5 \mathrm{~mm}$ cuboids using a Netzsch LFA 447 Nanoflash (Netzsch-Gerätebau GmbH, Selb, Germany).

\section{Results}

\section{1. $\mathrm{X} 65 \mathrm{MoCrWV3}-2$}

A coarse fraction of the gas-atomized tool steel powder was used in these experiments. A chemically identical, but finer fraction was used for PBF-LB experiments in [21]. Some characteristics of the as-received powder are listed in Table 1 . The measured $\mathrm{D}_{90}$ exceeds the specification. Microscopic images revealed deviations from spherical shape, specifically elongated particles, agglomerates, and satellites. Multiple recycling steps during the experiments removed some of the larger particles.

Table 1. Properties of the X65MoCrWV3-2 powder.

\begin{tabular}{cc}
\hline Dimension & Value \\
\hline $\mathrm{D}_{10}$ & $63.6 \mu \mathrm{m}$ \\
$\mathrm{D}_{50}$ & $93.5 \mu \mathrm{m}$ \\
$\mathrm{D}_{90}$ & $166.8 \mu \mathrm{m}$ \\
Apparent density & $4.12 \pm 0.00 \mathrm{~g} / \mathrm{cm}^{3}$ \\
Tap density & $4.72 \pm 0.08 \mathrm{~g} / \mathrm{cm}^{3}$ \\
Hall flow (50 g) & $18.5 \pm 0.0 \mathrm{~s}$ \\
Carbon content & $0.6 \mathrm{wt}-\%$ \\
\hline
\end{tabular}

The first aim of the parameter development was to fabricate test cubes with close to full density. To compare different parameter sets, the volumetric energy density $E_{V}$, defined as

$$
\mathrm{E}_{\mathrm{V}}=\frac{P}{v \cdot h \cdot t^{\prime}}
$$

has proved useful. It is the ratio between beam power $\mathrm{P}$, scan speed $\mathrm{v}$, hatch distance $\mathrm{h}$ and layer thickness $t$. As in other materials, a minimum $E_{V}$ is necessary for high density. For $\mathrm{X} 65 \mathrm{MoCrWV} 3-2$, the chosen layer thickness and preheat temperature this is approximately $25 \mathrm{~J} / \mathrm{mm}^{3}$. On the other hand, too high $E_{\mathrm{V}}$ above $50 \mathrm{~J} / \mathrm{mm}^{3}$ and high beam power will lead to swelling of the top surface.

Despite many high-density samples featuring smooth top surfaces, metallographic cross-sections revealed fine cracks, predominantly oriented in build direction. The density of those intergranular cracks was highest for large hatch spacings when keeping $E_{\mathrm{V}}$ constant [29]. Microscopic analysis revealed the segregation of refractory elements Molybdenum, Tungsten, and Vanadium to the grain boundaries as shown in Figure 1. There, the formation of brittle carbide precipitates likely initiates the cracks. 




Figure 1. SEM image of PBF-EB-processed X65MoCrWV3-2. The arrow marks the build direction. The table on the right side represents the elemental composition determined at the respective spots using EDX.

For smaller hatch distances the temperature gradient is modified, and crack-free samples could be obtained. The process window in Figure 2 summarizes the results for $50 \mu \mathrm{m}$ hatch distance. Within this, the formation of cracks was observed mainly for high scan speeds. Samples with more than $0.5 \%$ porosity are denoted as porous.

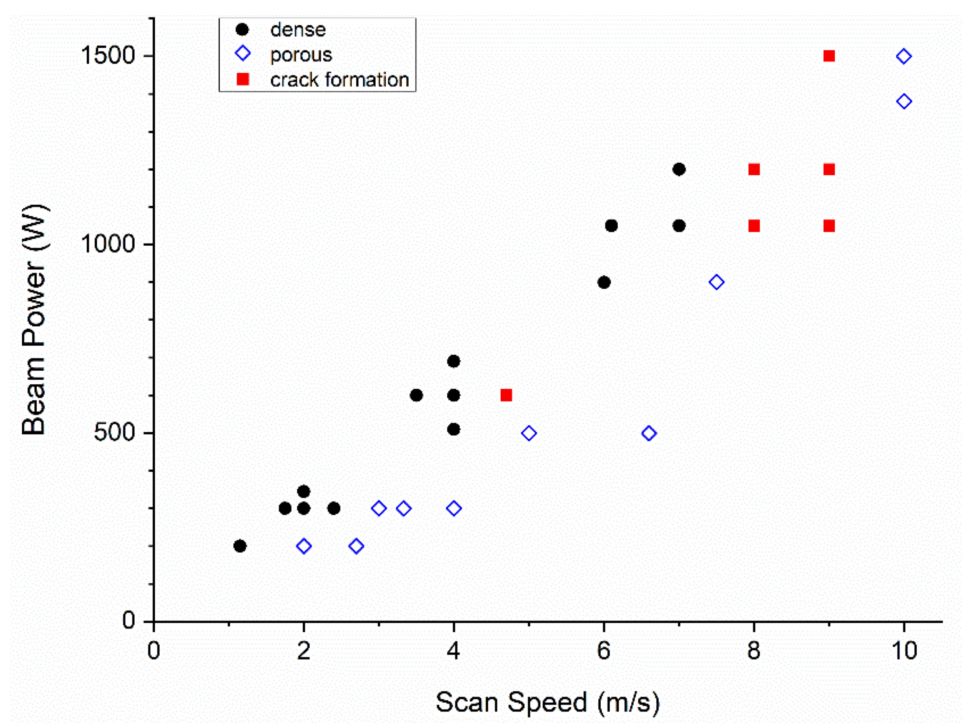

Figure 2. PBF-EB process window for X65MoCrWV3-2 for $70 \mu \mathrm{m}$ layer thickness and $50 \mu \mathrm{m}$ hatch distance. Full circles mark dense specimens, while open diamonds stand for porous materials and full squares for materials with cracks.

Figure 3 represents the microstructure of a crack-free and dense specimen fabricated with $E_{\mathrm{V}} 49 \mathrm{~J} / \mathrm{mm}^{3}$. The grains are elongated in the build direction to some extent. Their orientation deviates from the build direction in an alternating manner, suggesting the pattern was caused by the regularly changing scan direction. Other samples examined microscopically featured close to equiaxed grains. The chemical composition of the specimens has been analyzed and no difference was found to feedstock composition. The pick-up of contaminants such as $\mathrm{O}$ and $\mathrm{N}$ is negligible due to the vacuum environment in the working chamber. The measured oxygen content of the as-received powder is $100 \mathrm{ppm}$. After 20 build jobs the oxygen reaches 200 ppm. The same concentration of $200 \mathrm{ppm}$ oxygen is 
detected in the final part. The carbon content of the as-received powder is $0.61 \mathrm{wt}-\%$ and $0.59 \mathrm{wt}-\%$ in the PBF-EB material.

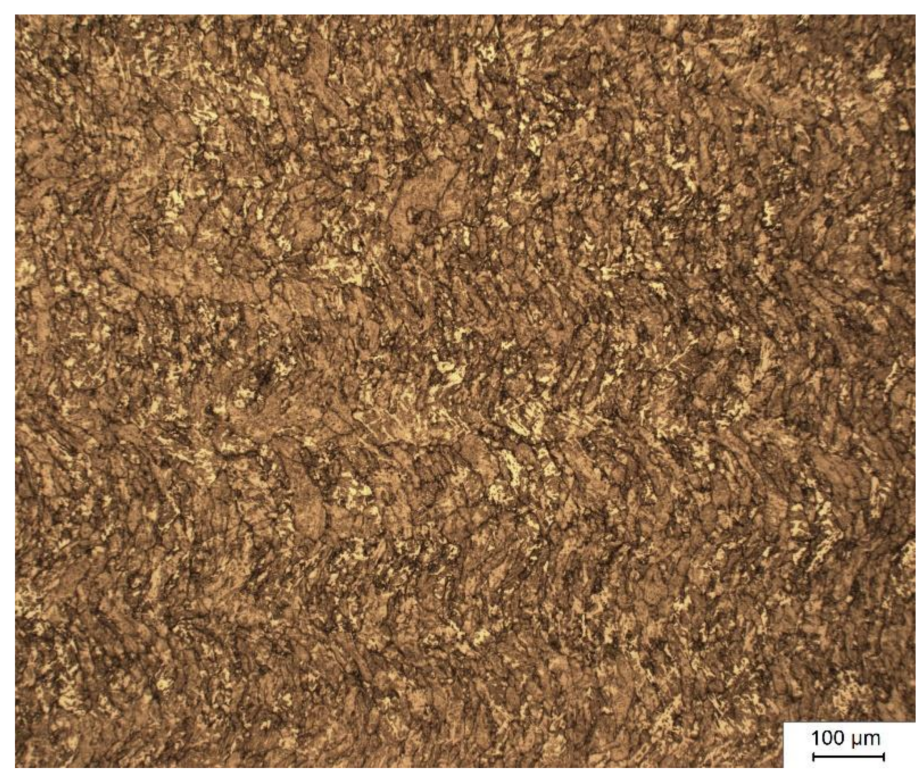

Figure 3. Optical micrograph of metallographic cross-section of PBF-EB processed X65MoCrWV3-2. Build direction is vertical. The main processing parameters were beam power $600 \mathrm{~W}$, scan speed $3500 \mathrm{~mm} / \mathrm{s}$, and hatch distance $50 \mu \mathrm{m}$.

In the as-built state, a hardness of $475 \mathrm{HV} 1$ was measured for the PBF-EB X65MoCrWV3-2. This value did not change upon tempering up to $500^{\circ} \mathrm{C}$, indicating a microstructure free of martensite. In contrast, the hardness after quench-hardening is $825 \mathrm{HV} 1$. Tempering the hardened samples at $400{ }^{\circ} \mathrm{C}$ leads to a reduction to $650 \mathrm{HV} 1$. A secondary hardening maximum is observed at $550{ }^{\circ} \mathrm{C}$ tempering temperature with $675 \mathrm{HV} 1$ hardness.

\subsection{X37CrMoV5-1}

Some fundamental properties of the virgin powder are summarized in Table 2. The powder was found suitable for processing with the Arcam PBF-EB equipment in its standard configuration.

Table 2. Properties of the X37CrMoV5-1 powder.

\begin{tabular}{cc}
\hline Dimension & Value \\
\hline $\mathrm{D}_{10}$ & $65.6 \mu \mathrm{m}$ \\
$\mathrm{D}_{50}$ & $89.4 \mu \mathrm{m}$ \\
$\mathrm{D}_{90}$ & $141.1 \mu \mathrm{m}$ \\
Apparent density & $4.11 \pm 0.00 \mathrm{~g} / \mathrm{cm}^{3}$ \\
Tap density & $4.76 \pm 0.00 \mathrm{~g} / \mathrm{cm}^{3}$ \\
Hall flow (50 g) & $17.1 \pm 0.1 \mathrm{~s}$ \\
\hline
\end{tabular}

Building cubes with $15 \mathrm{~mm}$ edge length, the melt parameter development was performed for $70 \mu \mathrm{m}$ layer thickness and $100 \mu \mathrm{m}$ hatch distance. To this end, the beam power was varied between $300 \mathrm{~W}$ to $750 \mathrm{~W}$, while scan speeds ranging from $750 \mathrm{~mm} / \mathrm{s}$ to $7500 \mathrm{~mm} / \mathrm{s}$ were employed, as shown in Figure 4. Lack of fusion porosity is observed in the specimens, with $E_{V}$ up to $28 \mathrm{~J} / \mathrm{mm}^{3}$. The porosity in these samples exceeds $0.5 \%$. Noticeable swelling of the melt surface with more than $1 \mathrm{~mm}$ deviation from planarity appears at higher beam power and $\mathrm{E}_{\mathrm{V}}$ of $57 \mathrm{~J} / \mathrm{mm}^{3}$, marking another limit to the process window. 


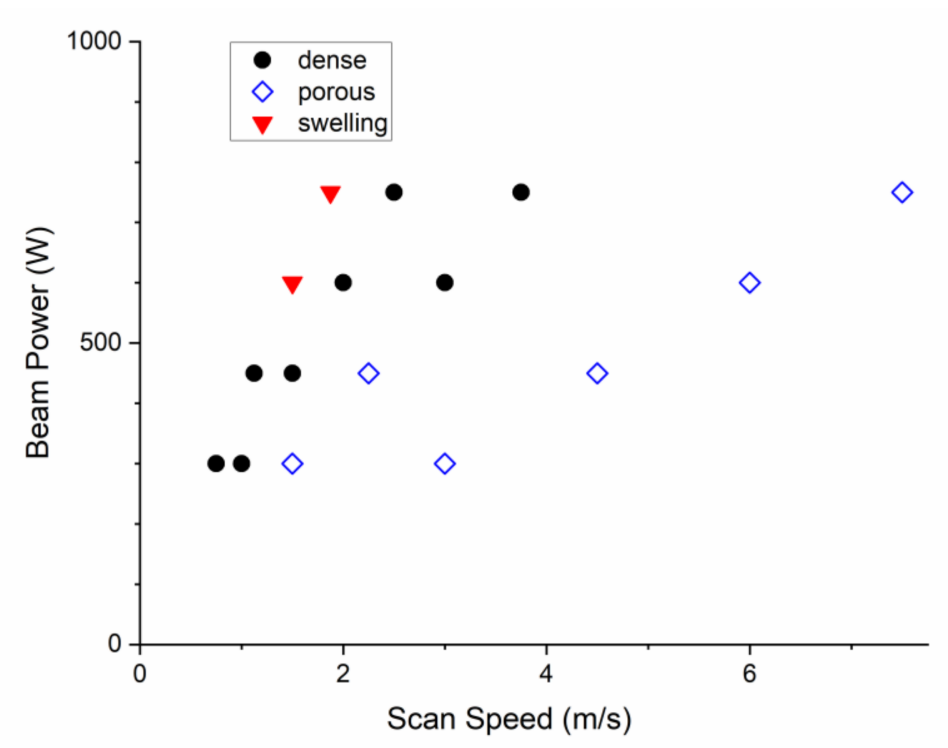

Figure 4. PBF-EB process window for X37CrMoV5-1 for $70 \mu \mathrm{m}$ layer thickness and $100 \mu \mathrm{m}$ hatch distance. Full circles mark dense specimen, while open diamonds stand for porous material and full triangles for strong swelling.

Metallographic analysis revealed the absence of microscopic cracks in all specimens analyzed. This includes further experiments with smaller hatch distances of $50 \mu \mathrm{m}$ and $75 \mu \mathrm{m}$. In dense samples, the remaining porosity is of spherical shape with diameters below $10 \mu \mathrm{m}$ and has a volume fraction below $0.1 \%$. Figure 5 shows the microstructure of a typical dense specimen using build parameters chosen for the tensile specimen. The observed grain sizes exhibit a wide range. Compared to X65MoCrWV3-2 the grains are coarser. Again, a certain elongation of the grain shape is present as well as an alternating misorientation with respect to the build direction.



Figure 5. Optical micrograph of metallographic cross-section of PBF-EB processed X37CrMoV5-1. Build direction is vertical. The main processing parameters were beam power $480 \mathrm{~W}$, scan speed $1530 \mathrm{~mm} / \mathrm{s}$ and hatch distance $50 \mu \mathrm{m}$.

Table 3 presents a comparison of the main alloying element content of the powder feedstock and the PBF-EB material. Within the error of measurement, it can be stated that the additive process did not alter the alloy composition. 
Table 3. Chemical composition of the X37CrMoV5-1 powder and PBF-EB specimen. All values in wt- $\%$.

\begin{tabular}{cccccc}
\hline & C & Cr & Mn & Mo & V \\
\hline Powder & 0.43 & $5.82 \pm 0.03$ & $0.72 \pm 0.002$ & $1.35 \pm 0.01$ & $0.46 \pm 0.002$ \\
PBF-EB material & 0.42 & $5.90 \pm 0.02$ & $0.66 \pm 0.003$ & $1.40 \pm 0.01$ & $0.46 \pm 0.005$ \\
\hline
\end{tabular}

Tensile tests were performed on PBF-EB X37CrMoV5-1 specimen in as-built condition in build direction and perpendicular to it. Figure 6 shows the data set tested in build direction. Table 4 contains the numerical values. The difference between the two testing directions is very small. Young's modulus is $185 \mathrm{GPa}$, yield strength approximately $950 \mathrm{MPa}$, ultimate tensile strength $1800 \mathrm{MPa}$ and elongation at break $4.5 \%$. The variation of the latter two is significantly larger in build direction.

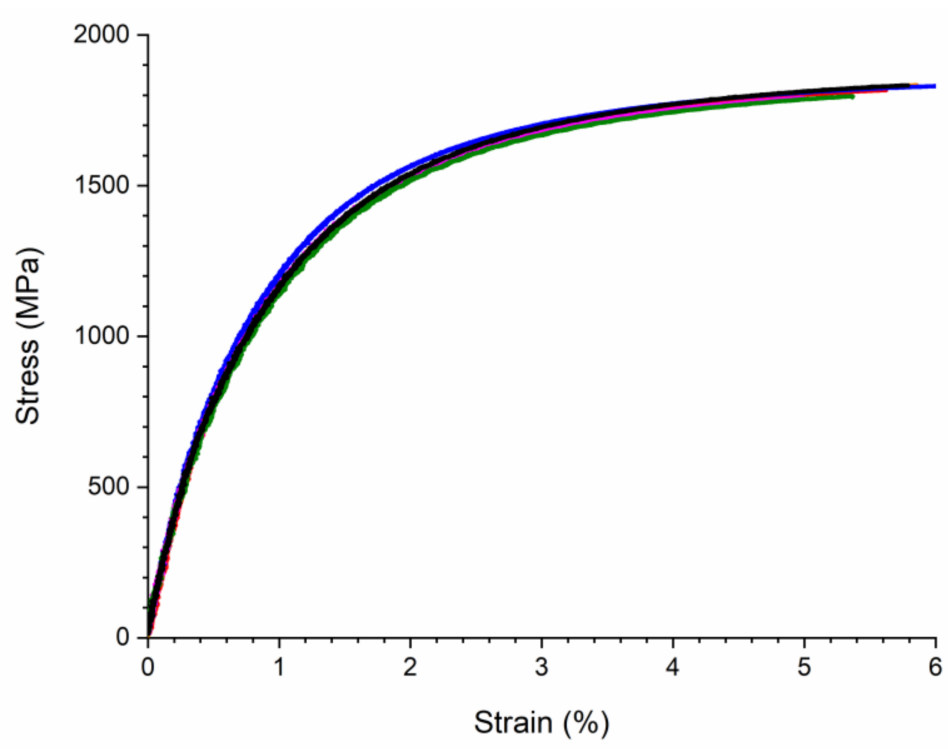

Figure 6. Stress-strain curves of tensile test of PBF-EB processed X37CrMoV5-1 tested in build direction $(\mathrm{N}=7)$.

Table 4. Tensile properties of the X37CrMoV5-1 PBF-EB specimen.

\begin{tabular}{ccccc}
\hline & E & YTS & UTS & A \\
\hline$Z$ & $184 \pm 4 \mathrm{GPa}$ & $952 \pm 7 \mathrm{MPa}$ & $1796 \pm 61 \mathrm{MPa}$ & $4.5 \pm 1.0 \%$ \\
$X, Y$ & $185 \pm 6 \mathrm{GPa}$ & $937 \pm 13 \mathrm{MPa}$ & $1805 \pm 22 \mathrm{MPa}$ & $4.5 \pm 0.5 \%$ \\
\hline
\end{tabular}

The thermal conductivity of the PBF-EB X37CrMoV5-1 material in as-built condition as calculated from thermal diffusivities of $5.34 \mathrm{~mm}^{2} / \mathrm{s}$ and $5.45 \mathrm{~m}^{2} / \mathrm{s}$ respectively, is $19.3 \mathrm{~W} / \mathrm{m} \cdot \mathrm{K}$ in build direction and $19.7 \mathrm{~W} / \mathrm{m} \cdot \mathrm{K}$ perpendicular to it.

The hardness of the PBF-EB X37CrMoV5-1 after quench-hardening is 696 HV10. Upon tempering, this is reduced, as detailed in Table 5.

Table 5. Vickers hardness of the heat-treated X37CrMoV5-1 PBF-EB specimen.

\begin{tabular}{ccccc}
\hline & Quench-Hardened & $\mathbf{5 0 0}{ }^{\circ} \mathbf{C}$ & $\mathbf{5 5 0}^{\circ} \mathbf{C}$ & $\mathbf{6 0 0}^{\circ} \mathbf{C}$ \\
\hline$($ HV 10) & $696 \pm 12$ & $689 \pm 4$ & $619 \pm 3$ & $470 \pm 2$ \\
\hline
\end{tabular}




\section{Discussion}

\subsection{X65MoCrWV3-2}

The additive manufacturing of X65MoCrWV3-2 by PBF-EB was successfully demonstrated for the first time. The susceptibility of the material to crack formation necessitated careful choice of the process parameters. Dense and crack-free parts were obtained for small hatch distances of $50 \mu \mathrm{m}$, moderate scan speeds and $E_{V}$ of $40 \mathrm{~J} / \mathrm{mm}^{3}$ to $50 \mathrm{~J} / \mathrm{mm}^{3}$. The explanation is seen in the influence of hatch spacing and scan speed on grain size and elongation. The observed microstructure shown in Figure 3 is homogeneous. Compared to processing by PBF-LB at much lower powder bed temperatures of $200{ }^{\circ} \mathrm{C}$ to $300{ }^{\circ} \mathrm{C}[11,21]$ the PBF-EB-built material lacks the presence of martensite and features coarser grains. This is reflected in the hardness of the as-built material. In the PBF-EB samples the hardness is 475 HV1 compared to approximately 700 HV0.1 in PBF-LB processed material.

During the additive process the chemical composition of the steel did not change significantly. Upon quench-hardening and tempering, hardness values were obtained that are practically identical to conventional material. A maximum hardness of $675 \mathrm{HV} 1$ is observed after tempering at $550{ }^{\circ} \mathrm{C}$.

It is worth noting that the developed process is suitable for fabrication of complex shaped parts. Figure 7a shows a feasibility demonstrator with overhangs that was manufactured without any support structures. Using the optimum parameter set for high-density and crack-free material, a build rate of $12 \mathrm{~cm}^{3} / \mathrm{h}$ is achieved.
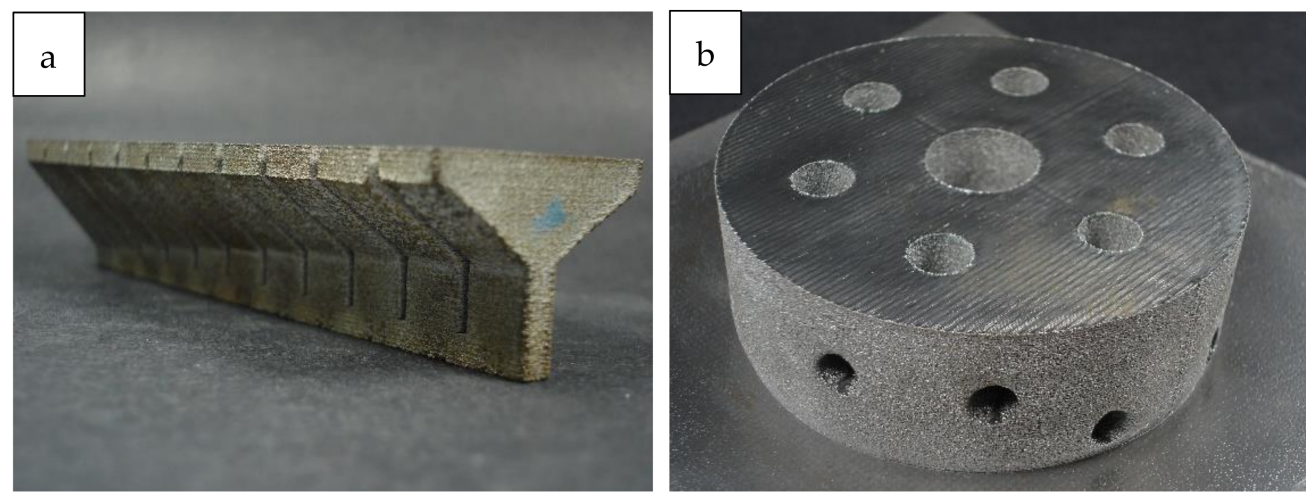

Figure 7. Demonstrator parts. (a) $130 \mathrm{~mm}$ long test piece manufactured by PBF-EB from X65MoCrWV3-2, demonstrating the ability to fabricate overhangs with angles up to $50^{\circ}$ without support structures. (b) Demonstrator part with complex internal channels fabricated by PBF-EB from X37CrMoV5-1. The main diameter is $90 \mathrm{~mm}$.

\subsection{X37CrMoV5-1}

PBF-EB processing of X37CrMoV5-1 resulted in high-density material. No cracks were found. While the resulting microstructure depicted in Figure 5 is characterized by grains elongated in build direction, the measured tensile properties are close to isotropic.

Comparing the results to PBF-LB processed X37CrMoV5-1, fundamental differences appear. The PBF-LB microstructure is predominantly bainitic [11]. Correspondingly, the asbuilt hardness is $642 \mathrm{HV} 1$ high. Ultimate tensile strength up to $2000 \mathrm{MPa}$ was measured in build direction, but only $1000 \mathrm{MPa}$ and very brittle behavior perpendicular to that. Due to the much higher powder bed temperature, the PBF-EB material reaches only $1800 \mathrm{MPa}$ UTS, but exhibits a ductility level of $4.5 \%$ in all directions. After hardening and annealing at $550{ }^{\circ} \mathrm{C}$ the PBF-LB material has a hardness of $585 \mathrm{HV} 1$, while that of the PBF-EB material is 619 HV10. In comparison to PBF-EB processed X40CrMoV5-1 [17] a 400-MPa-higher UTS was achieved in this study.

Benchmarking the PBF-EB material against conventionally fabricated X37CrMoV5-1, the hardness of the heat-treated additively manufactured steel is significantly higher than the $52 \mathrm{HRC}$ to $54 \mathrm{HRC}$ stated for annealing temperature up to $550^{\circ} \mathrm{C}$ [28]. In addition, the as-built ultimate tensile strength of the PBF-EB material is higher than the $1500 \mathrm{MPa}$ of the 
conventional material. The thermal conductivity of the as-built material is approximately $20 \%$ lower than the conventional steel [30].

In Figure $7 \mathrm{~b}$ a demonstrator part built with the above-mentioned parameters is displayed. It features an internal channel structure with multiple bends, from which powder was removed successfully. The build rate for X37CrMoV5-1 is $30 \mathrm{~cm}^{3} / \mathrm{h}$.

\section{Conclusions}

The results demonstrate the feasibility of the PBF-EB technology for additive manufacturing of the tool steels X65MoCrWV3-2 and X37CrMoV5-1. A fundamental finding is that after heat treatment, the PBF-EB tool steels can match their conventionally fabricated counterparts in important properties such as hardness. Further conclusions are

1. For X65MoCrWV3-2 a narrow process window for the fabrication of dense, crack-free parts exists. At $50 \mu \mathrm{m}$ hatch distance this corresponds to a volumetric energy density of $\sim 50 \mathrm{~J} / \mathrm{mm} 3$.

2. Higher scan speeds and hatch distances result in crack formation.

3. In PBF-EB X37CrMoV5-1 no cracks were detected. Therefore, a wider range of scan speeds and hatch distances can be applied.

4. No significant increase in impurities was detected after the PBF-EB process. In addition, the alloy composition did not change.

5. The as-built microstructure is fine-grained and free of martensite.

In the future a more comprehensive characterization of the additively manufactured steels will be necessary to understand their properties fully.

Author Contributions: Conceptualization, B.K., M.F.-J. and A.K.; experimental investigation, M.F.-J., L.I.R.-H. and A.K.; writing and editing, A.K., M.F.-J. and B.K.; supervision and resources, T.W. All authors have read and agreed to the published version of the manuscript.

Funding: This research was funded by the Federal Ministry of Education and Research, grant number 03XP0089C (research project AddMaTs).

Institutional Review Board Statement: Not applicable.

Data Availability Statement: The data that support the findings of this study are available from the corresponding author upon reasonable request.

Acknowledgments: The authors would like to acknowledge the support of the project partner Dörrenberg Edelstahl $\mathrm{GmbH}$, specifically the provision of X65MoCrWV3-2 powder and generation of data on hardenability.

Conflicts of Interest: The authors declare no conflict of interest.

\section{References}

1. Mezghani, A.; Nassar, A.R.; Dickman, C.J.; Valdes, E.; Alvarado, R. Laser powder bed fusion additive manufacturing of copper wicking structures: Fabrication and capillary characterization. Rapid Prototyp. J. 2021, 27, 1181-1188. [CrossRef]

2. DebRoy, T.; Wei, H.L.; Zuback, J.S.; Mukherjee, T.; Elmer, J.W.; Milewski, J.O.; Beese, A.M.; Wilson-Heid, A.; De, A.; Zhang, W. Additive manufacturing of metallic components-Process, structure and properties. Prog. Mater. Sci. 2018, 92, 112-224. [CrossRef]

3. Kempen, K.; Vrancken, B.; Buls, S.; Thijs, L.; van Humbeeck, J.; Kruth, J.-P. Selective laser melting of crack-free high density M2 high speed steel parts by baseplate preheating. J. Manuf. Sci. Eng. 2014, 136, 61026. [CrossRef]

4. Kumar, M.; Gibbons, G.J.; Das, A.; Manna, I.; Tanner, D.; Kotadia, H.R. Additive manufacturing of aluminium alloy 2024 by laser powder bed fusion: Microstructural evolution, defects and mechanical properties. Rapid Prototyp. J. 2021, 27, 1388-1397. [CrossRef]

5. Magana Carranza, R.; Robinson, J.; Ashton, I.; Fox, P.; Sutcliffe, C.; Patterson, E. A novel device for in-situ force measurements during laser powder bed fusion (L-PBF). Rapid Prototyp. J. 2021, 27, 1423-1431. [CrossRef]

6. Sander, J.; Hufenbach, J.K.; Giebeler, L.; Wendrock, H.; Kühn, U.; Eckert, J. Microstructure and properties of FeCrMoVC tool steel produced by selective laser melting. Mater. Des. 2016, 89, 335-341. [CrossRef]

7. Kruth, J.-P. Part and material properties in selective laser melting of metals. In Proceedings of the 16th International Symposium on Electromachining, Shanghai, China, 14 April 2010; pp. 3-14. 
8. Krell, J.; Röttger, A.; Geenen, K.; Theisen, W. General investigations on processing tool steel X40CrMoV5-1 with selective laser melting. J. Mater. Process. Technol. 2018, 255, 679-688. [CrossRef]

9. Simson, T.; Koch, J.; Rosenthal, J.; Kepka, M.; Zetek, M.; Zetkova, I.; Wolf, G.; Tomcik, P.; Kulhanek, J. Mechanical Properties of 18Ni-300 maraging steel manufactured by LPBF. Procedia Struct. Integr. 2019, 17, 843-849. [CrossRef]

10. Mooney, B.; Kourousis, K.I. A review of factors affecting the mechanical properties of maraging steel 300 fabricated via laser powder bed fusion. Metals 2020, 10, 1273. [CrossRef]

11. Bajaj, P.; Hariharan, A.; Kini, A.; Kürnsteiner, P.; Raabe, D.; Jägle, E.A. Steels in additive manufacturing: A review of their microstructure and properties. Mater. Sci. Eng. A 2020, 772, 138633. [CrossRef]

12. Haghdadi, N.; Laleh, M.; Moyle, M.; Primig, S. Additive manufacturing of steels: A review of achievements and challenges. J. Mater. Sci. 2021, 56, 64-107. [CrossRef]

13. Wang, J.; Liu, S.; Fang, Y.; He, Z. A short review on selective laser melting of H13 steel. Int. J. Adv. Manuf. Technol. 2020, 108, 2453-2466. [CrossRef]

14. Mertens, R.; Vrancken, B.; Holmstock, N.; Kinds, Y.; Kruth, J.-P.; Van Humbeeck, J. Influence of powder bed preheating on microstructure and mechanical properties of H13 tool steel SLM parts. Phys. Procedia 2016, 83, 882-890. [CrossRef]

15. Asberg, M.; Fredriksson, G.; Hatami, S.; Fredriksson, W.; Krakhmalev, P. Influence of post treatment on microstructure, porosity and mechanical properties of additive manufactured H13 tool steel. Mater. Sci. Eng. A 2019, 742, 584-589. [CrossRef]

16. Cormier, D.; Harrysson, O.; West, H. Characterization of $\mathrm{H} 13$ steel produced via electron beam melting. Rapid Prototyp. J. 2004, 10, 35-41. [CrossRef]

17. Rännar, L.E.; Glad, A.; Gustafson, C.G. Efficient cooling with tool inserts manufactured by electron beam melting. Rapid Prototyp. J. 2007, 13, 128-135. [CrossRef]

18. Kahlert, M.; Brenne, F.; Vollmer, M.; Niendorf, T. Influence of microstructure and defects on mechanical properties of AISI H13 manufactured by electron beam powder bed fusion. J. Mater. Eng. Perform. 2021, 30, 6895-6904. [CrossRef]

19. Casati, R.; Coduri, M.; Lecis, N.; Andrianopoli, C.; Vedani, M. Microstructure and mechanical behavior of hot-work tool steels processed by selective laser melting. Mater. Charact. 2018, 137, 50-57. [CrossRef]

20. Huber, F.; Bischof, C.; Hentschel, O.; Heberle, J.; Zettl, J.; Nagulin, K.Y.; Schmidt, M. Laser beam melting and heat-treatment of 1.2343 (AISI H11) tool steel-Microstructure and mechanical properties. Mater. Sci. Eng. 2019, 742, 109-115. [CrossRef]

21. Boes, J.; Röttger, A.; Mutke, C.; Escher, C.; Theisen, W. Microstructure and mechanical properties of X65MoCrWV3-2 cold-work tool steel produced by selective laser melting. Addit. Manuf. 2018, 23, 170-180. [CrossRef]

22. Boes, J.; Röttger, A.; Theisen, W. Processing of X65MoCrWV3-2 cold work tool steel by laser powder bed fusion. Steel Res. Int. 2020, 91, 1900445. [CrossRef]

23. Botero, C.; Ramsperger, M.; Selte, A.; Asvik, K.; Koptyug, A.; Skoglund, P.; Roos, S.; Rännar, L.-E.; Bäckström, M. Additive manufacturing of a cold-work tool steel using electron beam melting. Steel Res. Int. 2019, 91, 1900448. [CrossRef]

24. Botero, C.A.; Selte, A.; Ramsperger, M.; Maistro, G.; Koptyug, A.; Bäckström, M.; Sjöström, W.; Rännar, L.-E. Microstructural and mechanical evaluation of a Cr-Mo-V cold-work tool steel produced via electron beam melting (EBM). Materials 2021, 14, 2963. [CrossRef] [PubMed]

25. Liu, Z.H.; Zhang, D.Q.; Chua, C.K.; Leong, K.F. Crystal structure analysis of M2 high speed steel parts produced by selective laser melting. Mater. Charact. 2013, 84, 72-80. [CrossRef]

26. He, Y.; Zhong, M.; Jones, N.; Beuth, J.; Webler, B. The columnar-to-equiaxed transition in melt pools during laser powder bed fusion of M2 steel. Metall. Mater. Trans. A 2021, 52, 4206-4221. [CrossRef]

27. CP2M. Available online: https://www.doerrenberg.de/wp-content/uploads/2020/05/CP2M\%C2\%AE_en.pdf (accessed on 27 September 2021).

28. Thermodur 2343. Available online: https://www.dew-stahl.com/fileadmin/files/dew-stahl.com/documents/Publikationen/ Werkstoffdatenblaetter/Werkzeugstahl/Warmarbeitsstahl/GB_Thermodur2343.pdf (accessed on 27 September 2021).

29. Jurisch, M.; Escher, C.; Kirchner, A.; Klöden, B.; Weißgärber, T.; Kieback, B. Processing of tool steels by Electron Beam Melting. In Fraunhofer Direct Digital Manufacturing Conference DDMC 2018 Proceedings; 2018. Available online: https:/ / www.bookshop. fraunhofer.de/buch/Fraunhofer-Direct-Digital-Manufacturing-Conference-DDMC-2018/249002 (accessed on 11 October 2021).

30. 1.2343-Werkstoff 1.2343 Datenblatt. Available online: https:/ /www.stauberstahl.com/werkstoffe/12343-werkstoff-datenblatt/ (accessed on 9 August 2021). 